\title{
RAMAN SPECTRUM OF ETHYL CHLOROACETATE
}

\author{
By P. Neelakantan \\ (Department of Physics, Indian Institute of Science, Bangalore-12) \\ Received February 27, 1964 \\ (Communicated by Professor R. S. Krishnan, F.A.Sc.)

\section{INTRODUCTION}

IT has been shown in the case of monohaloacetates that the carbonyl frequency splits up into two due to rotational isomerism involving a rotation about the $\mathrm{C}-\mathrm{C}$ bond, joining the asymmetric group $\mathrm{CH}_{2} \mathrm{X}$ (where $\mathrm{X}=\mathrm{F}$, $\mathrm{Cl}$ or $\mathrm{Br}$ ) to the carbonyl (Josien and Castinel, 1958; Josien and Calas, 1955; Brown, 1958). Recently, Brown (1962) has studied the temperature dependence of the intensity of the carbonyl band in $\mathrm{RCOOC}_{2} \mathrm{H}_{5}$ for $\mathrm{R}=\mathrm{CH}_{2} \mathrm{Cl}$, $\mathrm{CH}_{2} \mathrm{~F}, \mathrm{CH}_{2} \mathrm{Br}$ and $\mathrm{CHCl}_{2}$ and from these studies he has calculated the $\triangle \mathrm{H}$ for equilibrium between the high and low frequency conformations.

The Raman spectrum of ethyl chloroacetate has been studied earlier by Pal and Sen Gupta (1930). Subsequent work on its Raman spectrum has been on the intensity of the carbonyl frequency (Michel and Duyckaerts, 1958; Michel, 1959). In the present investigation, the Raman spectrum of ethyl chloroacetate has been taken at about $13^{\circ} \mathrm{C} ., 28^{\circ} \mathrm{C}$. and $78^{\circ} \mathrm{C}$. in order to estimate the relative proportion of the isomers and its dependence on temperature.

\section{EXPERImental Details}

Ethyl chloroacetate (Pure Chemicals Ltd.) was purified by distillation before use. A horizontal cylindrical low pressure mercury arc of special design was constructed and used as the source for taking the Raman spectrum.

The Raman spectra were taken with a Hilger two-prism spectrograph. $\lambda 4358$ radiation of mercury was used as the exciter for the Raman spectra of ethyl chloroacetate at $28^{\circ} \mathrm{C}$. and $78^{\circ} \mathrm{C}$. However, both $\lambda 4046$ and $\lambda 4358$ excitation were used for recording the Raman spectrum of ethyl chloroacetate taken at about $13^{\circ} \mathrm{C}$. Agfa Raman Orthochromatic plates were used for recording all the spectra.

\section{RESULTS}

Figure $1(a)$ of Plate XVIII gives the Raman spectrum of ethyl chloroaceate with $\lambda 4358$ excitation and $1(b)$ its microphotometer record. Figures 
$2(a)$ and $2(b)$ of plate XIX give microphotometer records of the Raman spectra of ethyl chloroacetate at about $13^{\circ} \mathrm{C}$. and $78^{\circ} \mathrm{C}$.

In columns (1) and (2) of Table I are given the frequency shifts of the observed Raman lines of ethyl acetate and ethyl chloroacetate. Table II gives the $\mathrm{C}=\mathrm{O}$ stretching frequencies at $13^{\circ} \mathrm{C}$., $28^{\circ} \mathrm{C}$. and $78^{\circ} \mathrm{C}$., along with the values reported by Josien and Castinel from infra-red studies.

\section{Discussion}

Michel and Duyckaerts (1958) have observed for ethyl chloroacetate two Raman lines one at $1740 \mathrm{~cm} .^{-1}$ and the other at $1754 \mathrm{~cm} .^{-1}$ due to $\mathrm{C}=\mathrm{O}$ stretching vibration. In infra-red absorption also the carbonyl band is found to be split up into two (Brown, 1958; Josien and Castinel, 1958). In the present study it has been found likewise, that the carbonyl stretching frequency is split up into two, in all the spectra taken at the three temperatures. The splitting of the carbonyl has been explained by the earlier investigators on the basis of inductive effects and the lower frequency Raman line is, in accordance with the arguments of Bellamy and Williams (1957), to be attributed to the gauche isomer and the higher frequency line due to the cis isomer.

Table II gives the $\mathrm{C}=\mathrm{O}$ stretching frequencies of ethyl chloroacetate at three different temperatures. Contrary to the normal influence of temperature, the frequency increases slightly for both the isomers with rise of temperature. From the microphotometer records, one can see, that at $13^{\circ} \mathrm{C}$., both the lines are almost of equal intensity, but as the temperature increases, the higher frequency Raman line due to the cis isomer decreases in intensity while the line due to the gauche isomer increases in intensity. Hence, one can expect, in the vapour state, the gauche isomer to predominate and the corresponding carbonyl frequency to shift to higher values. This is in agreement with the observations made by Josien and Castinel (loc. cit.). According to them in monohaloacetates, a single band (often fairly broad) which is observed in infra-red absorpton spectra in the gaseous state corresponds to the lower of the two carbonyl frequencies in solution even though it coincides with the higher frequency. The values reported by them are given in Table II.

For ethyl chloroacetate, McBee and Christman (1955) have assigned the infra-red absorption band at $697 \mathrm{~cm}^{-1}$ to the $\mathrm{C}-\mathrm{Cl}$ stretching frequency. According to Hua-Chih Cheng and Lecomte (1935), for the compounds $\mathrm{ClCH}_{2}-\mathrm{R}$, a single frequency characteristic of the halogen is displaced from 740 to $790 \mathrm{~cm}^{-1}$ when $R$ is replaced successively by the groups $\mathrm{CN}, \mathrm{COH}$, $\mathrm{COCl}, \mathrm{COOH}$ and $\mathrm{COO} \mathrm{C}_{n} \mathrm{H}_{2 n}+1$. For ethyl chloroacetate, since there 
TABLE I

Frequency shifts of the Raman lines

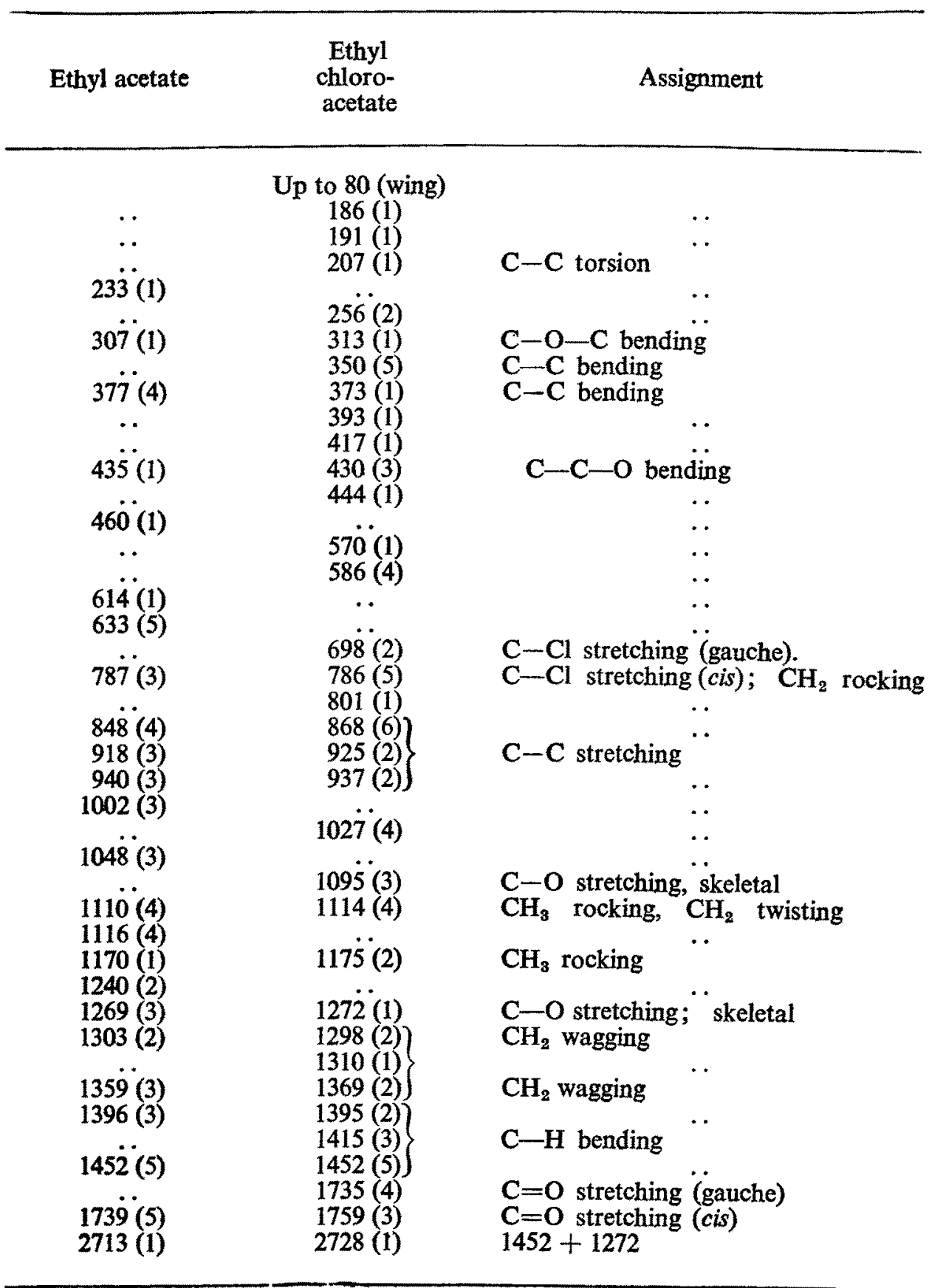


TABLE I (Contd.)

\begin{tabular}{|c|c|c|c|c|}
\hline Ethyl acetate & $\begin{array}{l}\text { Ethyl } \\
\text { chloro- } \\
\text { acetate }\end{array}$ & & \multicolumn{2}{|c|}{ Assignment } \\
\hline $\begin{array}{c}2878(4) \\
2902(6) \\
2940(8) \\
2982(6)\end{array}$ & $\begin{array}{l}2878(4) \\
2903(6) \\
2937(8) \\
2970(8) \\
2985(7)\end{array}$ & \multicolumn{3}{|c|}{ C-H stretching } \\
\hline \multicolumn{5}{|c|}{$\begin{array}{c}\text { TabLe II } \\
\text { Stretching frequencies }\end{array}$} \\
\hline \multicolumn{3}{|c|}{ Raman spectra } & \multicolumn{2}{|c|}{ Infra-red } \\
\hline $13^{\circ} \mathrm{C}$ & $28^{\circ} \mathrm{C}$ & $78^{\circ} \mathrm{C}$ & $\underset{\text { solution }}{\mathrm{CCl}_{4}}$ & $\begin{array}{l}\text { In } \\
\text { vapour } \\
\text { state }\end{array}$ \\
\hline 1734 & 1735 & 1740 & 1742 & 1766 \\
\hline 1755 & 1759 & 1763 & 1767 & $\ldots$ \\
\hline
\end{tabular}

are two isomers, on the basis of an argument, analogous to that used for explaining the splitting of the carbonyl frequency, one can expect two Raman lines corresponding to $\mathrm{C}-\mathrm{Cl}$ stretching vibrations. The Raman lines at 698 and $786 \mathrm{~cm} .^{-1}$ can, therefore, be assigned to the $\mathrm{C}-\mathrm{Cl}$ stretching vibrations. But it appears that the strong Raman line at $786 \mathrm{~cm}^{-1}$ is not entirely due to $\mathrm{C}-\mathrm{Cl}$ stretching vibration, for in ethyl acetate there is a weak Raman line at about $788 \mathrm{~cm} .^{-1}$ which may be due to $\mathrm{CH}_{2}$ rocking vibration. So the strong Raman line at $786 \mathrm{~cm}^{-1}$, in ethyl chloroacetate, may be due to $\mathrm{C}-\mathrm{Cl}$ stretching and $\mathrm{CH}_{2}$ rocking vibrations. On account of this superposition of a line due to the $\mathrm{CH}_{2}$ rocking mode on the $\mathrm{C}-\mathrm{Cl}$ stretching frequency, it is not possible to draw any quantitative conclusions about the changes in the relative proportion of the isomers with temperature from the changes in the intensities of the Raman lines due to $\mathrm{C}-\mathrm{Cl}$ stretching vibrations.

It can also be seen from the microphotometer records, that the Raman lines at 925 and $1095 \mathrm{~cm}^{-1}$ increase in intensity with temperature whereas 
the line at $937 \mathrm{~cm} .^{-1}$ decreases in intensity, although the changes in intensities are not much.

Pal and Sen Gupta (loc. cit.) have observed six Raman lines in ethyl chloroacetate having frequency shifts $786,876,1429,2880,2937$ and $2976 \mathrm{~cm}^{-1}$ In the present study, for ethyl chloroacetate 38 Raman lines have been observed. Because of the low symmetry of this molecule and also because of the presence of considerable number of fundamentals, it is difficult to give an unambiguous assignment for all the observed frequencies. Still an attempt has been made to assign the observed lines in comparison with the spectrum of ethyl acetate (see Table I).

\section{SUMMARY}

The Raman spectrum of ethyl chloroacetate has been studied at $13^{\circ} \mathrm{C}$., $28^{\circ} \mathrm{C}$. and $78^{\circ} \mathrm{C}$. The carbonyl frequency was found to be split up into two due to the presence of rotational isomers. The higher frequency line due to the cis isomer was found to decrease in intensity with temperature. It appears that the gauche isomer will predominate in the vapour state. Altogether thirty-eight Raman lines have been recorded. Reasonable assignments for the observed Raman lines were made in comparison with ethyl acetate spictrum.

\section{ACKNOWLEDGEMENT}

I wish to express my grateful thanks to Professor R. S. Krishnan for his valuable guidance and encouragement and to Dr. P. S. Narayanan for his suggestions.

\section{REFERENCES}

1. Bellamy, L. J, and Williams, R. L.

J. Chem. Soc., 1957, 4294.

2. Brown, T. L.

.. J. Amer. Chem. Soc., 1958, 80, 3513.

3.

.. Spectrochimica Acta, 1962, 18, 1615.

4. Hua-Chih Cheng and Comp. Rend., 1935, 201, 199. Lecomte, J.

5. Josien, M. L. and Calas, R. Ibid., 1955, 240, 1641.

6. - and Castinel, $\mathrm{C}$. Bull. Soc. Chimie France, 1958, 801.

7. McBee, E. T. and Christiman, D. L.

8. Michel, G. J. Amer. Chem. Soc., 1955, 77, 755.

9. and Duyckaerts, $G$. Bull. Soc. Chimie Belges, 1959, 68, 643.

10. Pal, N. N. and Sen Gupta, P. N. 


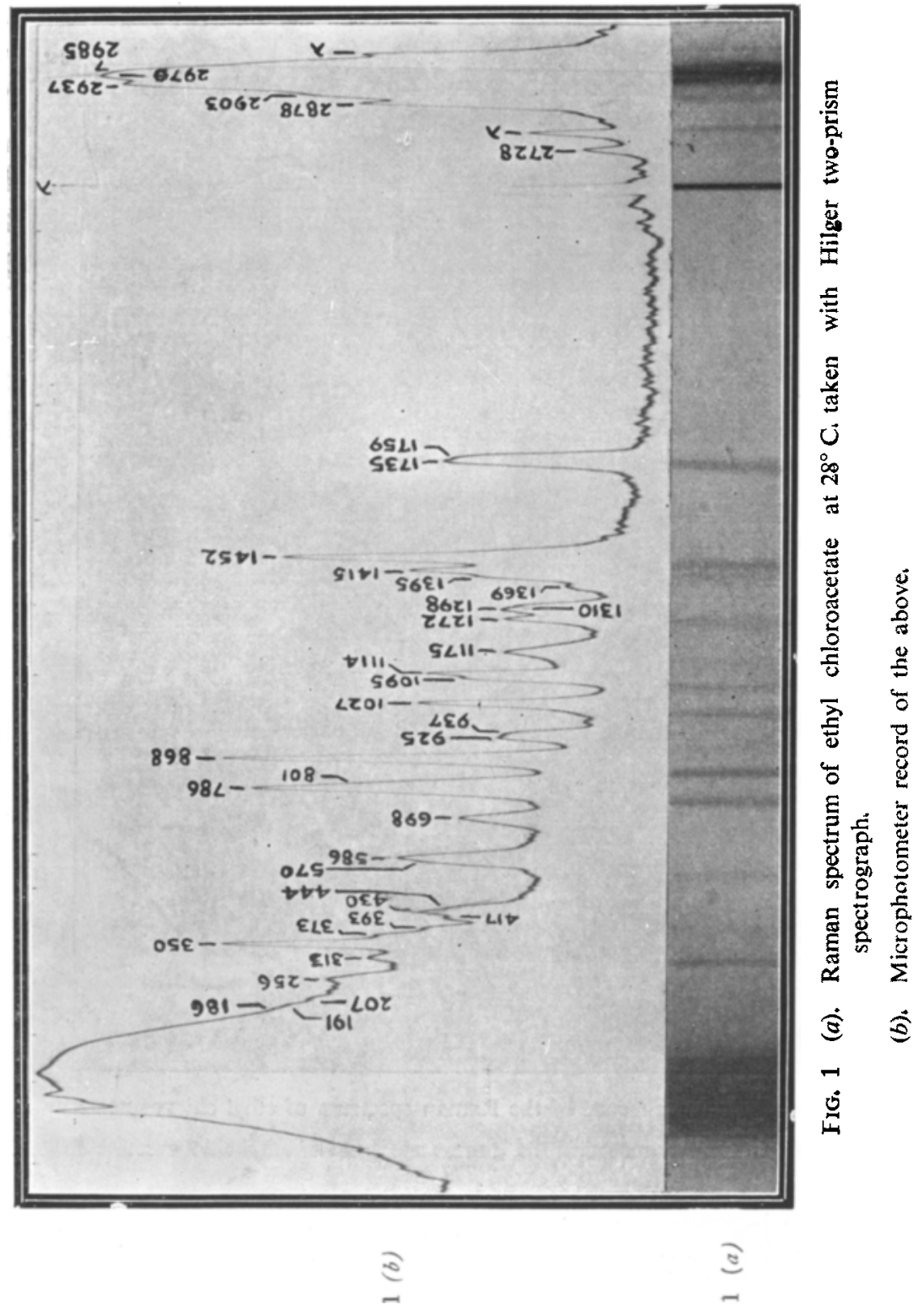




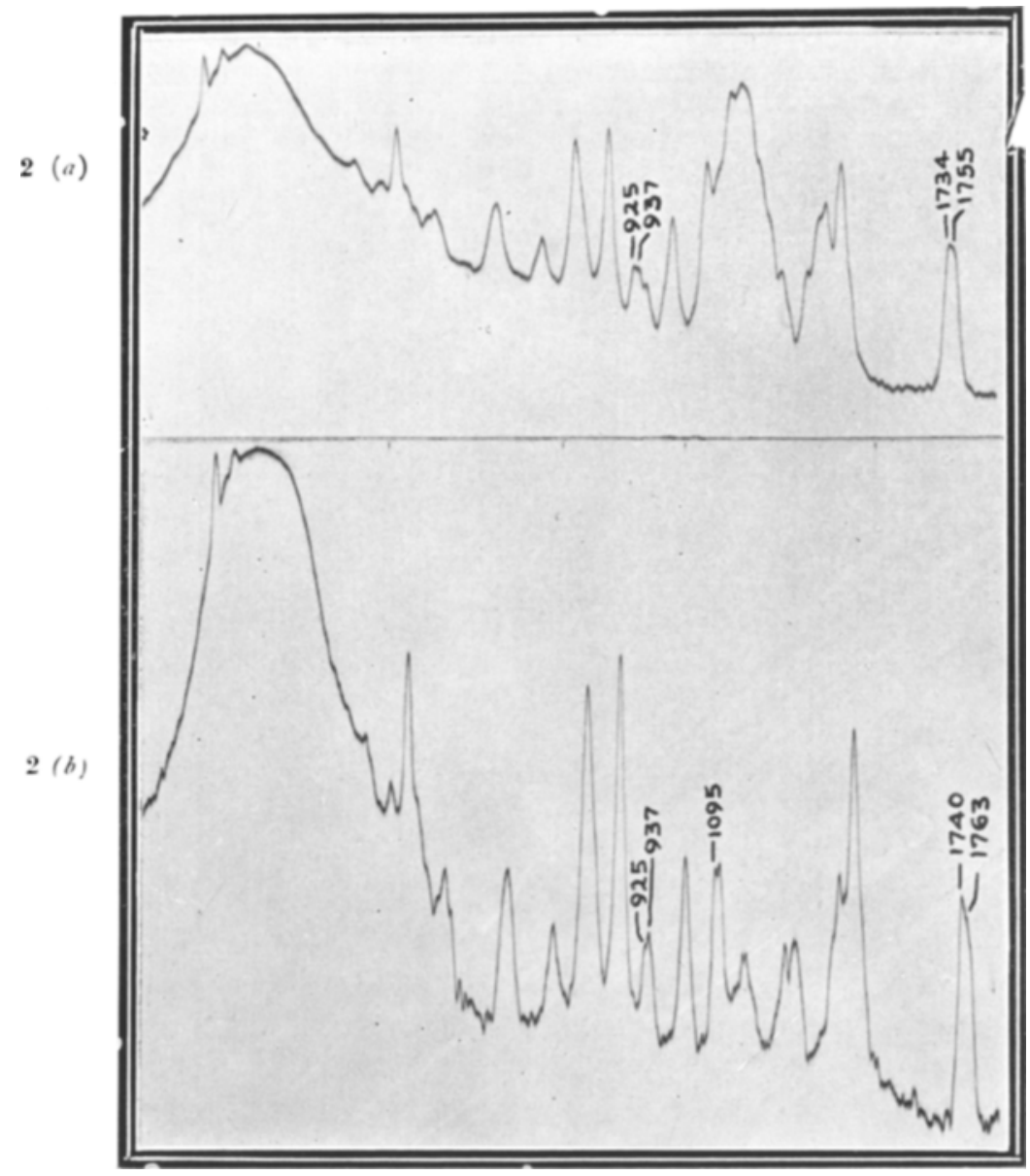

Frg. $2(a)$. Microphotometer record of the Raman spectrum of ethyl chloroacetate at $13^{\circ} \mathrm{C}$.

(b). Microphotometer record of the Raman spectrum of ethyl chloroacetate at $78^{\circ} \mathrm{C}$. 